\title{
A PRESUNÇÃO DE INOCÊNCIA COMO UM DIREITO HUMANO FUNDAMENTAL NA CONSTITUIÇÃO BRASILEIRA E SUA APLICAÇÃO PELO SUPREMO TRIBUNAL FEDERAL
}

\author{
THE PRESUMPTION OF INNOCENCE AS A FUNDAMENTAL HUMAN RIGHT IN \\ THE BRAZILIAN CONSTITUTION AND ITS APPLICATION BY THE SUPREME \\ FEDERAL COURT
}

\author{
LA PRESUNCIÓN DE INOCENCIA COMO UN DERECHO HUMANO \\ FUNDAMENTAL EN LA CONSTITUCIÓN BRASILEÑA Y SU APLICACIÓN POR \\ EL SUPREMO TRIBUNAL FEDERAL
}

\begin{abstract}
SAMYRA HAYDÊE DAL FARRA NASPOLINI
https://orcid.org/0000-0002-1838-9005 / http:// lattes.cnpq.br/4529730931640744 / samyranaspolini@gmail.com Universidade de Marília - UNIMAR e Centro Universitário das faculdades Metropolitanas Unidas - FMU São Paulo, SP, Brasil.

VLADMIR OLIVEIRA DA SILVEIRA

https://orcid.org/0000-0002-8374-3920 / http://lattes.cnpq.br/5229046964889778 / vladmir@aus.com.br Universidade Federal do Mato Grosso do Sul - UFMS

Campo Grande, MS, Brasil.
\end{abstract}

\section{RESUMO}

O presente artigo investiga a formação histórica da presunção de inocência e a sua consagração na normativa internacional de proteção aos Direitos Humanos como a Declaração Universal e a Convenção Americana. Também investiga a recepção pelo Brasil dessa normativa e o seu corolário na Constituição Federal de 1988. A problemática enfrentada pela pesquisa é, sendo o Supremo Tribunal Federal o guardião da Constituição Federal, decidiu conforme o princípio constitucional de presunção de inocência ao admitir a prisão após condenação em segunda instância, mesmo sem ter transitado em julgado a sentença condenatória? Conclui que o princípio constitucional foi violado uma vez que a Constituição é clara ao estabelecer que o estado de Inocência prevalecerá até o trânsito em julgado de sentença penal condenatória. A pesquisa foi realizada pela técnica da pesquisa bibliográfica e de julgados, os principais conceitos necessários para atingir o objetivo almejado.

Palavras-chave: Direito Internacional dos Direitos Humanos; Direitos Fundamentais; Presunção de Inocência; Processo Penal Constitucional.

\begin{abstract}
This article investigates the historical formation of the presumption of innocence and its establishment in international norms of protection of Human Rights such as the Universal Declaration and the American Convention. It also investigates the reception by Brazil of such legislation and its corollary in the Brazilian Federal Constitution of 1988. The problem faced by the research is, being the Brazilian Supreme Court the guardian of the Constitution, and according to the constitutional principle of presumption of innocence, how it is possible to be admitted an arrest after conviction in the second instance, even without a final sentence having been passed? It is concluded that the constitutional principle has been violated since the Constitution is clear in establishing that the State of Innocence shall prevail until the final sentence of conviction has passed. The research was carried out by means of bibliographical research and of jurisprudence, in which the main concepts were explored in order to achieve the desired goal.
\end{abstract}

Keywords: International Human Rights Law; Fundamental rights; Presumption of Innocence; Constitutional Criminal Procedure. 
A PRESUNCCÃO DE INOCÊNCIA COMO UM DIREITO HUMANO FUNDAMENTAL NÁ CONSTITUIÇÃO BRASILEIRA E SUA APLICAÇÃO PELO SUPREMO TRIBUNAL FEDERAL SAMYRA HAYDÊE DAL FARRA NASPOLINI VLADMIR OLIVEIRA DA SILVEIRA

\section{RESUMEN}

El presente artículo investiga la formación histórica de la presunción de inocencia y su consagración en la normativa internacional de protección a los Derechos Humanos como la Declaración Universal y la Convención Americana. También investiga la recepción por Brasil de esa normativa y su corolario en la Constitución Federal de 1988. La problemática enfrentada por la investigación es, siendo el Supremo Tribunal Federal el guardián de la Constitución Federal, decidió conforme al principio constitucional de presunción de inocencia al admitir la prisión después condenación en segunda instancia, aun sin haber transitado en sentencia la sentencia condenatoria? Concluye que el principio constitucional fue violado una vez que la Constitución es clara al establecer que el estado de Inocencia prevalecerá hasta el tránsito en juzgado de sentencia penal condenatoria. La investigación fue realizada por la técnica de la investigación bibliográfica y de juzgados, los principales conceptos necesarios para alcanzar el objetivo anhelado.

Palabras clave: Derecho Internacional de los Derechos Humanos; Derechos Fundamentales; Presunción de Inocencia; Proceso Penal Constitucional.

\section{SUMÁRIO}

INTRODUÇÃO; 1 PRESUNÇÃO DE INOCÊNCIA OU ESTADO DE INOCÊNCIA; 2 PRESUNÇÃO DE INOCÊNCIA NO GARANTISMO PENAL; 3 A PRESUNÇÃO DE INOCÊNCIA NA NORMATIVA INTERNACIONAL DE PROTEÇÃO AOS DIREITOS HUMANOS; 4 A PRESUNÇÃO DE INOCÊNCIA NA CONSTITUIÇÃO BRASILEIRA E O SEU ENTENDIMENTO NO SUPREMO TRIBUNAL FEDERAL; CONCLUSÃO; REFERÊNCIAS.

\section{INTRODUÇÃO}

O presente artigo tem por objeto o princípio da presunção de inocência como um Direito Humano Fundamental e sua aplicação pelo Supremo Tribunal Federal brasileiro.

Para tanto, investiga a formação histórica da presunção de inocência e a sua consagração na normativa internacional de proteção aos Direitos Humanos como a Declaração Universal e a Convenção Americana. Também investiga a recepção pelo Brasil dessa normativa e o seu corolário na Constituição Federal de 1988.

A problemática enfrentada pela pesquisa é, sendo o Supremo Tribunal Federal o guardião da Constituição Federal, decidiu conforme o princípio constitucional de presunção de inocência ao admitir a prisão após condenação em segunda instância, mesmo sem ter transitado em julgado a sentença condenatória? A hipótese da pesquisa é a de que o princípio constitucional foi violado uma vez que a Constituição é clara ao estabelecer que o estado de Inocência prevalecerá até o trânsito em julgado de sentença penal condenatória.

No primeiro item discute-se a melhor nomenclatura para o tema pesquisado, se seria presunção de inocência ou estado de inocência, no segundo item estuda-se a presunção de inocência na perspectiva do garantismo penal, no terceiro a consagração da presunção de inocência na normativa internacional de proteção aos Direito Humanos e por fim analisa-se o entendimento da presunção de inocência pelo Supremo Tribunal Federal. 
Trata-se de um artigo de caráter exploratório e de revisão conceitual, que buscará investigar, pela técnica da pesquisa bibliográfica e de julgados, os principais conceitos necessários para atingir o objetivo almejado.

Importante mencionar que até a publicação do presente artigo não foram votadas as Ações Diretas de Inconstitucionalidade 43 e 44 sobre o tema que tramitam no Supremo Tribunal Federal.

\section{PRESUNÇÃO DE INOCÊNCIA OU ESTADO DE INOCÊNCIA}

Historicamente, pode-se encontrar o princípio da presunção de inocência em vários documentos que reconheceram este como um direito dos súditos e depois dos cidadãos, desde a Magna Carta de 1215, do Bill of Rights de 1690 até chegar na sua melhor expressão nas Declarações de Direitos do século XVII.

Estas Declarações, que inauguram a primeira dimensão dos Direitos Humanos, encontraram o seu fundamento na teoria jurídica designada de Direito Natural, que está situada nos séculos XVII e XVIII ${ }^{1}$, e foi elaborada em um intenso período de eventos históricos, como o desenvolvimento capitalista do mercado, o fim da cristandade, a conquista da América e a afirmação do Estado nacional. ${ }^{2}$

Direitos inatos oriundos da razão, estado de natureza e contrato social foram, os principais conceitos que caracterizaram o jusnaturalismo deste período e "permitiram a elaboração de uma doutrina do Direito e do Estado a partir da concepção individualista de sociedade e da história, que marca o aparecimento do mundo moderno."

Assim, pode-se situar o surgimento dos Direitos Humanos de primeira dimensão, quais sejam, os diretos de liberdade, igualdade formal, vida, e diversas garantias processuais como a presunção de inocência, no Estado Moderno Liberal, que nasce devido a busca de um limite ao poder soberano, sendo a razão desse limite os direitos inerentes ao homem, os quais couberam ao Estado preservar, mesmo quando exerce o seu monopólio do direito/dever de punir.

\footnotetext{
${ }^{1}$ NASPOLINI SANCHES, Samyra. H D. F.Direitos humanos e empresa privada no Brasil. IN: COUTO, Mônica Bonetti. (Org); MAILLART, Adriana Silva (Org); MEYER-PFLUG, Samantha Ribeiro (Org); MEZZAROBA, Orides (Coord); NASPOLINI SANCHES, Samyra. H D. F. (Org); SILVEIRA, Vladmir Oliveira da (Coord). Empresa, sustentabilidade e funcionalização do direito. São Paulo: Editora Livraria dos Tribunais, 2011. p. 294307.

2 LOPES, José Reinaldo de Lima. O direito na história: lições introdutórias. 2. ed. São Paulo: Max Limonad, 2002. p. 179.

${ }^{3}$ LAFER, Celso. A reconstrução dos direitos humanos: um diálogo com o pensamento de Hannah Arendt. São Paulo: Companhia das letras, 1988. p. 38.
} 
A PRESUNÇÃO DE INOCÊNCIA COMO UM DIREITO HUMANO FUNDAMENTAL NA CONSTITUIÇÃO BRASILEIRA E SUA APLICAÇÃO PELO SUPREMO TRIBUNAL FEDERAL SAMYRA HAYDÊE DAL FARRA NASPOLINI VLADMIR OLIVEIRA DA SILVEIRA

Declarado na Revolução Francesa, e inserido na Constituição daquele país, foi recebido pela Declaração Universal dos Direitos Humanos, pela Declaração Americana de Direito Humanos e no Brasil ele só veio a ser estabelecido na chamada Constituição Cidadã, a Constituição de 1988.

Diferentemente de autores que tratam a inocência consagrada nas normativas internacionais de proteção aos Direitos Humanos e no artigo $5^{\circ}$ da nossa Constituição Federal como uma "presunção de inocência", Eugênio Pacelli de Oliveira adota o termo "estado ou situação jurídica de inocente". Segundo ao autor, este Estado de Inocência é um:

[...] tratamento, segundo o qual o réu, em nenhum momento do inter persecutório, pode sofrer restrições pessoais fundadas exclusivamente na possibilidade de condenação, e a outra, de fundo probatório, a estabelecer que todos os ônus da prova relativa à existência do fato e à sua autoria devem recair exclusivamente sobre a acusação. Na prática cria-se uma presunção de culpa contrária ao acusado, que terá desde o início da persecução criminal uma carga de contraprovar sua inocência, alterando-se os primados mais subliminares do processo penal constitucionalizado, que por sua vez deve ser o norte do Estado Democrático de Direito. ${ }^{4}$

Como será visto, o Estado de Inocência como garantia constitucional irá condicionar todo o processo penal determinando que é assim deve permanecer o suspeito de um delito, até sentença condenatória irrecorrível.

José Joaquim Gomes Canotilho ${ }^{5}$ chama a presunção de inocência de princípio garantia, por se tratar de "autêntica norma jurídica, com força determinante, positiva ou negativa", orientando a hermenêutica constitucional e formatando a atuação do Estado positiva ou negativamente.

\section{A PRESUNÇÃO DE INOCÊNCIA NO GARANTISMO PENAL}

A teoria geral do garantismo surge a partir da matriz iluminista da época da ilustração, sendo responsável pela elaboração de argumentos filosóficos, jurídicos e políticos que darão surgimento ao Estado de Direito. 6

\footnotetext{
${ }^{4}$ OLIVEIRA, Eugênio Pacelli de. Regimes Constitucionais da Liberdade Provisória. Rio de Janeiro: Lúmen Júris, 2007. P 31.

5 CANOTILHO, José Joaquim Gomes. Direito Constitucional e Teoria da Constituição. 6. ed. Lisboa: Almedina, 1993. p. 196.

${ }^{6}$ CADEMARTORI, Sérgio. Estado de direito e legitimidade: uma abordagem garantista. Porto Alegre: Livraria do Advogado, 1999. p. 72.
} 
A PRESUNÇÃO DE INOCÊNCIA COMO UM DIREITO HUMANO FUNDAMENTAL NÁ CONSTITUIÇÃO BRASILEIRA E SUA APLICAÇÃO PELO SUPREMO TRIBUNAL FEDERAL SAMYRA HAYDÊE DAL FARRA NASPOLINI VLADMIR OLIVEIRA DA SILVEIRA

Este surgimento deve-se à busca de limites ao Estado frente à liberdade individual, sendo que passou a caber ao Direito Penal e ao Direito Processual Penal a atuação como parâmetros de tutela desta liberdade. Conforme afirma Carvalho, o "rol de direitos e garantias asseguradas pelo pensamento ilustrado propiciou a noção contemporânea de direitos de primeira geração (direitos individuais), estruturando a base de legitimidade do garantismo jurídico". 7

Em sua versão contemporânea, a teoria geral do garantismo foi formulada por Luigi Ferrajoli em 1989 em sua obra Diritto e Razione. Nesse sentido, Ferrajoli parte da ideia de que o Estado de Direito atual, apesar de conservar-se normativamente como garantista, tem apresentado tendências neoabsolutistas, especialmente no que diz respeito à legislação penal de emergência e de exceção.

Dentro da lógica garantista, a lei penal deve ser uma resposta somente aos problemas sociais gerais e duradouros, não devendo direcionar-se a situações atípicas e excepcionais. Devese preservar as características de generalidade e abstração da lei penal, ressaltando a ameaça às garantias jurídicas inerentes ao Estado de direito que constitui a legislação penal de emergência. ${ }^{8}$

No processo penal, as respostas contingentes implicam em um endurecimento do processo, com o aumento de atos em segredo, violação da intimidade e privacidade, aumento das penas processuais como prisões cautelares, crimes inafiançáveis e também a inversão da carga da prova com mais poderes para os juízes investigarem. ${ }^{9}$

Neste sentido, Lopes Júnior defende a ideia da utilização do processo penal como uma técnica de limitação do poder de punir, ou seja, garantia negativa, atuando como um instrumento com dupla função “de um lado, tornar viável a aplicação da pena, e de outro, servir como efetivo instrumento de garantia dos direitos e liberdades individuais, assegurando os indivíduos contra os atos abusivos do Estado" (grifo do autor). ${ }^{10}$

Dentro da perspectiva garantista a legitimação substancial do poder punitivo do Estado corresponde à legalidade estrita implicando na observação das garantias penais e processuais penais expressas nos seguintes princípios: 1) Princípio de retributividade (Não há pena sem crime); 2) Princípio de legalidade (Não há crime sem lei); 3) Princípio de necessidade ou da

\footnotetext{
${ }^{7}$ CARVALHO, Salo. Pena e garantias. 2. ed. Rio de Janeiro: Lumen Juris, 2003. p. 01.

8 BARATTA, Alessandro. Estado del derecho, derechos fundamentales y "derecho judicial". Revista de Ciencia Jurídica, San José da Costa Rica, n. 57, p. 119-134, mayo/ago. 1987. p. 559-595.

9 LOPES JUNIOR, Aury. Introdução crítica ao processo penal: fundamentos da instrumentalidade garantista. 2. ed. Rio de Janeiro: Lumen Juris, 2005. p. 151.

10 LOPES JUNIOR, Aury. Introdução crítica ao processo penal: fundamentos da instrumentalidade garantista. 2. ed. Rio de Janeiro: Lumen Juris, 2005. p. 37.
} 
A PRESUNÇÃO DE INOCÊNCIA COMO UM DIREITO HUMANO FUNDAMENTAL NÁ CONSTITUIÇÃO BRASILEIRA E SUA APLICAÇÃO PELO SUPREMO TRIBUNAL FEDERAL SAMYRA HAYDÊE DAL FARRA NASPOLINI VLADMIR OLIVEIRA DA SILVEIRA

Economia do Direito (Não há lei penal sem necessidade); 4) Princípio da Lesividade (Não há necessidade sem injúria); 5) Princípio de Materialidade ou da Exterioridade da Ação (Não há injúria sem ação); 6) Princípio de Culpabilidade ou de Responsabilidade Pessoal (Não há ação sem culpa); 7) Princípio da Jurisdicionalidade. (Não há culpa sem julgamento); 8) Princípio Acusatório ou de separação entre juiz e acusação (Não há julgamento sem acusação); 9) Princípio da carga da prova ou de verificação (Não há acusação sem prova) e 10) Princípio do Contraditório ou da Defesa ou da Refutação (Não há prova sem defesa). ${ }^{11}$

Em específico, insere-se no escopo da presente pesquisa o princípio de número 9 , o Princípio da Carga da Prova, segundo o qual não há acusação sem prova, ou seja, toda pessoa é admitida como inocente até que se prove em contrário mediante um processo com amplo contraditório e ampla defesa (Princípio 10), sendo que a carga da prova cabe a quem acusa.

Também decorrente das ideias iluministas como necessidade de proteger o cidadão do poder punitivo do Estado que o presumia culpado e buscava a todo preço a sua condenação, o princípio da presunção de inocência segundo Ferrajoli, expressa que "A culpa e não a inocência deve ser demonstrada; e é a prova da culpa e não da inocência que se presume desde o princípio, a que forma o objeto do juízo". ${ }^{12}$

Neste sentido, Ferrajoli considera a prisão cautelar como verdadeira pena antecipada e defende a sua exclusão do processo penal. ${ }^{13}$ Para ele: "como se pode falar em delito sem que tenha sido pronunciada uma sentença, nem como seja possível infligir uma pena sempre sem uma sentença prévia". ${ }^{14}$

Ao longo dos anos, e após a Declaração dos Direitos do Homem, os Direitos Fundamentais dos cidadãos foram sendo incorporados às Constituições de vários países. ${ }^{15}$ Entre nós, a Constituição atual, em seu art. $5^{\circ}$, apresenta extenso rol de normas destinadas a assegurar os direitos individuais e coletivos. A defesa do garantismo no processo penal, significa a defesa dos direitos e garantias fundamentais do cidadão, inseridos nos nossos princípios constitucionais, conforme será visto nos próximos itens.

\footnotetext{
11 FERRAJOLI, Luigi. Derecho y razón: teoría del garantismo penal. Trad. Perfecto Andrés Ibánez et al. Madri: Trotta, 1995. p. 93.

12 FERRAJOLI, Luigi. Derecho y razón: teoría del garantismo penal. Trad. Perfecto Andrés Ibánez et al. Madri: Trotta, 1995. p. 549.

${ }^{13}$ FERRAJOLI, Luigi. Derecho y razón: teoría del garantismo penal. Trad. Perfecto Andrés Ibánez et al. Madri: Trotta, 1995. p. 559.

14 FERRAJOLI, Luigi. Direito e Razão: teoria do garantismo penal. São Paulo: Editora Revista do Tribunais, 2006, p. 506.

${ }^{15}$ VIEIRA, Oscar Vilhena. Direitos humanos: normativa internacional. São Paulo: Max Limonad, 2001.
} 


\section{A PRESUNÇÃO DE INOCÊNCIA NA NORMATIVA INTERNACIONAL DE PROTEÇÃO AOS DIREITOS HUMANOS}

Com o fim da Segunda Guerra Mundial inicia-se o processo de universalização e internacionalização dos Direitos Humanos, uma vez que se tornaram uma legítima preocupação internacional, encerrando-se um período no qual perdurou a concepção de que a forma como o Estado tratava seu povo era concebida como um problema de jurisdição exclusivamente doméstica devido à soberania. Ao contrário, a relação do Estado com os seus nacionais passou a ser uma problemática internacional. ${ }^{16}$

Assim, o processo de universalização e internacionalização dos Direitos Humanos trouxe a necessidade de implementação desses mediante a criação de um Sistema Internacional de proteção, monitoramento e controle, o qual foi dividido em Sistema Global de proteção e Sistema Regional de proteção, complementares e indivisíveis esses não substituem os tribunais internos e não são tribunais de recurso ou cassação, ao contrário, trata-se de direito complementar ao direito nacional.

Nesse sentido, "a presença da sociedade internacional é imprescindível na união de esforços para a construção deste novo paradigma, na medida em que inclui na agenda global a preocupação com [...] temas difusos e globais" O Estado tem a responsabilidade primária pela proteção desses direitos e a comunidade internacional tem a responsabilidade subsidiária, porém os atos internos dos Estados podem vir a ser objeto de exame dos tribunais internacionais. ${ }^{17}$

O Sistema Global de proteção é composto pela Carta das Nações Unidas de 1945, integrada posteriormente pela Declaração Universal de Direitos Humanos de 1948 e pelos dois Pactos Internacionais de 1966: o Pacto Internacional sobre Direitos Civis e Políticos e o Pacto Internacional sobre Direitos Econômicos, Sociais e Culturais.

Ambos os Pactos possuem como principal objetivo dar concretude aos direitos já consagrados na Declaração Universal, “atribuindo-lhes valor jurídico na acepção positivista - o que os tornaria obrigatórios. No mesmo sentido, criou vinculações para os Estados-partes,

\footnotetext{
${ }^{16}$ CANÇADO TRINDADE, Antônio Augusto. Tratado de Direito Internacional dos Direitos Humanos. Volume I. Porto Alegre: Editora Sérgio Antônio Fabris, 1997, p. 33.

17 PIOVESAN, Flávia. Introdução ao Sistema Interamericano de proteção dos direitos humanos: A Convenção Americana dos Direitos Humanos. In. PIOVESAN, Flávia; GOMES, Luiz Flávio (Coord.). O Sistema de Proteção dos Direitos Humanos e o Direito Brasileiro. São Paulo: Ed. Revista dos Tribunais, 2000.
} 
A PRESUNCCÃO DE INOCÊNCIA COMO UM DIREITO HUMANO FUNDAMENTAL NÁ CONSTITUIÇÃO BRASILEIRA E SUA APLICAÇÃO PELO SUPREMO TRIBUNAL FEDERAL SAMYRA HAYDÊE DAL FARRA NASPOLINI VLADMIR OLIVEIRA DA SILVEIRA

abrindo a possibilidade de responsabilizá-los no plano internacional por atos atentatórios aos direitos humanos."18

Por sua vez, os Sistemas Regionais buscam internacionalizar os Direitos Humanos no plano regional. Enquanto o Sistema Global fornece um parâmetro normativo mínimo, o regional deve ir além, buscando concretizar os direitos já existentes e adicionar novos, tudo isso levando em consideração as diferenças entre as regiões. Atualmente a Europa, a América e a África já possuem aparato jurídico próprio. ${ }^{19}$

$\mathrm{Na}$ Declaração Universal dos Direitos Humanos pode-se encontrar a presunção de inocência em suas três implicações, como regra de tratamento do acusado, regra de prova, e como regra de juízo:

\section{Artigo XI}

Toda pessoa acusada de um ato delituoso tem o direito de ser presumida inocente até que a sua culpabilidade tenha sido provada de acordo com a lei, em julgamento público no qual the tenham sido asseguradas todas as garantias necessárias à sua defesa.

Ninguém poderá ser culpado por qualquer ação ou omissão que, no momento, não constituíam delito perante o direito nacional ou internacional. Tampouco será imposta pena mais forte do que aquela que, no momento da prática, era aplicável ao ato delituoso.

A Presunção de Inocência é novamente consagrada no Pacto sobre Direitos Civis e Políticos em seus art. 9 e 14:

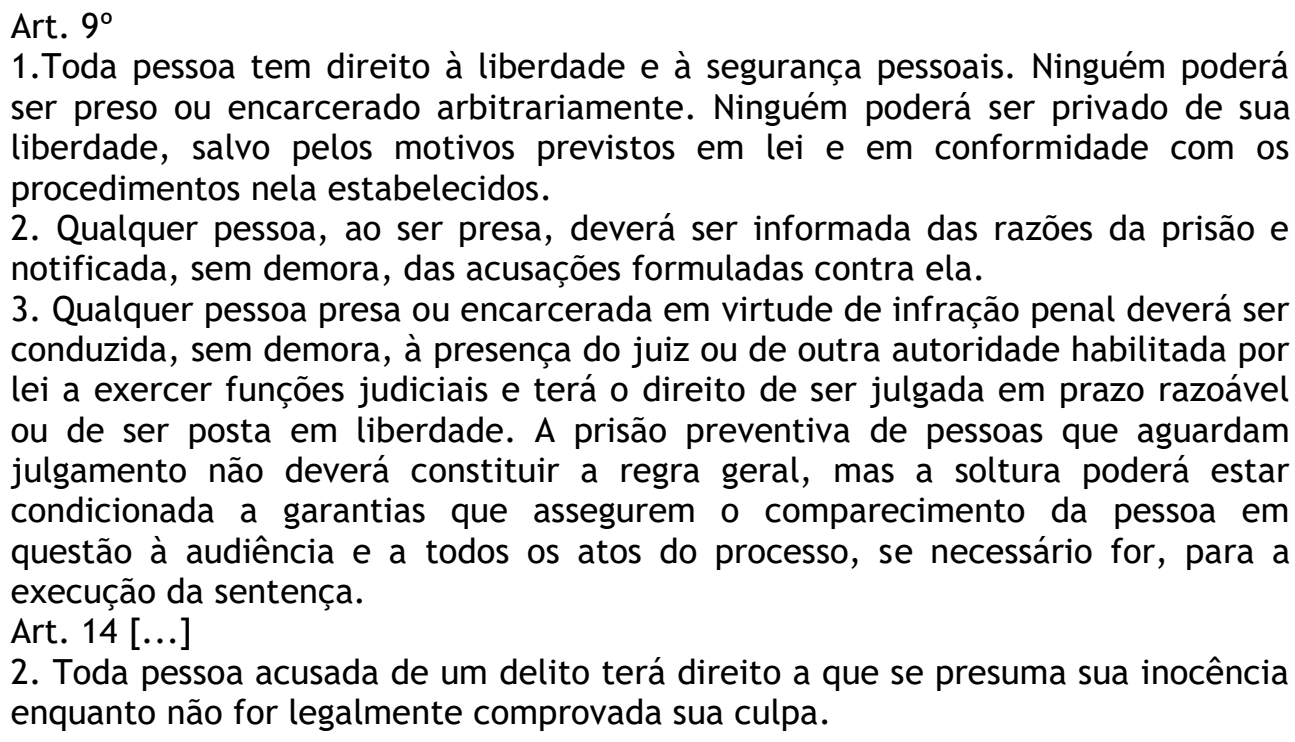
ser preso ou encarcerado arbitrariamente. Ninguém poderá ser privado de sua liberdade, salvo pelos motivos previstos em lei e em conformidade com os procedimentos nela estabelecidos.

2. Qualquer pessoa, ao ser presa, deverá ser informada das razões da prisão e notificada, sem demora, das acusações formuladas contra ela.

3. Qualquer pessoa presa ou encarcerada em virtude de infração penal deverá ser conduzida, sem demora, à presença do juiz ou de outra autoridade habilitada por lei a exercer funções judiciais e terá o direito de ser julgada em prazo razoável ou de ser posta em liberdade. A prisão preventiva de pessoas que aguardam julgamento não deverá constituir a regra geral, mas a soltura poderá estar condicionada a garantias que assegurem o comparecimento da pessoa em questão à audiência e a todos os atos do processo, se necessário for, para a execução da sentença.

Art. $14[\ldots]$

2. Toda pessoa acusada de um delito terá direito a que se presuma sua inocência enquanto não for legalmente comprovada sua culpa.

\footnotetext{
${ }^{18}$ ROCASOLANO, Maria Mendez ; SILVEIRA, Vladmir Oliveira; Direitos Humanos: conceitos, significados e funções. São Paulo: Saraiva, 2010. p. 158.

19 PIOVESAN, Flávia. Direitos Humanos e Justiça Internacional. São Paulo: Ed. Saraiva, 2007, p. 100.
} 
A PRESUNCCÃO DE INOCÊNCIA COMO UM DIREITO HUMANO FUNDAMENTAL NÁ CONSTITUIÇÃO BRASILEIRA E SUA APLICAÇÃO PELO SUPREMO TRIBUNAL FEDERAL

SAMYRA HAYDÊE DAL FARRA NASPOLINI VLADMIR OLIVEIRA DA SILVEIRA

Percebe-se, portanto, o início de uma nova era em que o foco do processo penal são as garantias do ser humano com comandos claros e objetivos no sentido de limitar a ação do poder de punir do estado em face da liberdade individual.

$\mathrm{Na}$ América, a Organização dos Estados Americanos (OEA), congrega os países do Hemisfério Ocidental, com o fim de fortalecer a cooperação e desenvolver interesses comuns. Trata-se do principal fórum para o diálogo multilateral e a ação concentrada na região americana. ${ }^{20}$

A OEA tem como ponto central de sua missão o compromisso inquestionável de defesa da democracia. Em novembro de 1969, foi realizada em São José de Costa Rica a Conferência Especializada Interamericana sobre Direitos Humanos. Nessa oportunidade, os Estados americanos assinaram a Convenção Americana dos Direitos Humanos, também conhecida como Pacto de San José que criou o Sistema Interamericano dos Direitos Humanos, composto por sua legislação, a Comissão Interamericana de Direitos Humanos e a Corte Interamericana de Direitos Humanos.

Em seu artigo $8^{\circ}$, itens I e II o Pacto de San José traz uma descrição muito precisa sobre a presunção de inocência em conjunto com regras de tratamento do acusado, são as Regras Judiciais do devido processo legal:

\section{Artigo $8^{\circ}$ - Garantias judiciais}

1. Toda pessoa tem direito a ser ouvida, com as devidas garantias e dentro de um prazo razoável, por um juiz ou tribunal competente, independente e imparcial, estabelecido anteriormente por lei, na apuração de qualquer acusação penal formulada contra ela, ou para que se determinem seus direitos ou obrigações de natureza civil, trabalhista, fiscal ou de qualquer outra natureza.

2. Toda pessoa acusada de delito tem direito a que se presuma sua inocência enquanto não se comprove legalmente sua culpa. Durante o processo, toda pessoa tem direito, em plena igualdade, às seguintes garantias mínimas:

a) direito do acusado de ser assistido gratuitamente por tradutor ou intérprete, se não compreender ou não falar o idioma do juízo ou tribunal;

b) comunicação prévia e pormenorizada ao acusado da acusação formulada; c) concessão ao acusado do tempo e dos meios adequados para a preparação de sua defesa;

d) direito do acusado de defender-se pessoalmente ou de ser assistido por um defensor de sua escolha e de comunicar-se, livremente e em particular, com seu defensor;

e) direito irrenunciável de ser assistido por um defensor proporcionado pelo Estado, remunerado ou não, segundo a legislação interna, se o acusado não se defender ele próprio nem nomear defensor dentro do prazo estabelecido pela lei; f) direito da defesa de inquirir as testemunhas presentes no tribunal e de obter o comparecimento, como testemunhas ou peritos, de outras pessoas que possam lançar luz sobre os fatos;

${ }^{20}$ A OEA foi constituída por intermédio da Carta da Organização dos Estados Americanos, reformada pelo Protocolo de Buenos Aires em 1967, pelo Protocolo de Cartagena das Índias em 1985, pelo Protocolo de Washington em 1992 e pelo Protocolo de Manágua em 1993. 


\section{UDIREITO}

A PRESUNÇÃO DE INOCÊNCIA COMO UM DIREITO HUMANO FUNDAMENTAL NA CONSTITUIÇÃO BRASILEIRA E SUA APLICAÇÃO PELO SUPREMO TRIBUNAL FEDERAL SAMYRA HAYDÊE DAL FARRA NASPOLINI VLADMIR OLIVEIRA DA SILVEIRA

g) direito de não ser obrigado a depor contra si mesma, nem a declarar-se culpada; e

h) direito de recorrer da sentença a juiz ou tribunal superior.

Assim, fica o Estado proibido de tomar qualquer medida que venha a ser considerada como antecipação de pena, ou imputar ao acusado o ônus de produzir as provas de sua inocência. No mesmo sentido todas as provas produzidas no processo devem obtidas obedecendo pelos meios autorizados pela lei, assegurando-se sempre o contraditório e a ampla defesa.

Nos seus Comentários a Convenção Americana sobre Direitos Humanos, Gomes e Mazzuoli ${ }^{21}$ ao tratar do princípio da presunção de inocência apresentam uma paradigmática decisão da Corte Interamericana:

Caso Cantoral Benavidez, sentença em 18.08.2000, parágrafo 119: “Como regra de tratamento a presunção de inocência impede qualquer antecipação de juízo condenatório ou de reconhecimento da culpabilidade do imputado, seja por situações, práticas, palavras, gestos etc., podendo-se exemplificar: a impropriedade de se manter o acusado em exposição humilhante no banco dos réus, o uso de algemas quando desnecessário, a divulgação abusiva de fatos e nomes de pessoas pelos meios de comunicação, a decretação ou manutenção de prisão cautelar desnecessária, a exigência de se recolher à prisão para apelar em razão da existência de condenação em primeira instância. É contraria a presunção de inocência a exibição de uma pessoa nos meios de comunicação vestida com traje infamante.

O Brasil aprovou o texto da Carta Americana em 26 de maio de 1992, tendo o seu texto integrado a normativa jurídica interna, em 06 de novembro de 1992, por meio do Decreto Presidencial de $\mathrm{n}^{\circ} 678$, formalizando a possibilidade de exigibilidade dos termos da Convenção como compromisso assumido perante a comunidade internacional das Américas e a afirmação destes direitos como garantias dos indivíduos que estão em território brasileiro.

\section{A PRESUNÇÃO DE INOCÊNCIA NA CONSTITUIÇÃO BRASILEIRA E O SEU ENTENDIMENTO NO SUPREMO TRIBUNAL FEDERAL}

No contexto histórico de defesa do Estado Democrático de Direito, a Constituição Federal de 1988 consagrou, no rol dos Direitos Fundamentais, a presunção de inocência em sua acepção mais ampla:

Art. $5^{\circ}$ - Todos são iguais perante a lei, sem distinção de qualquer natureza, garantindo-se aos brasileiros e aos estrangeiros residentes no País a

${ }^{21}$ GOMES, Flávio; MAZZUOLI, Valério de Oliveira. Comentários à Convenção Americana sobre Direitos Humanos. São Paulo: Ed. Revista dos Tribunais, 2010, p. 106. 
A PRESUNÇÃO DE INOCÊNCIA COMO UM DIREITO HUMANO FUNDAMENTAL NÁ CONSTITUIÇÃO BRASILEIRA E SUA APLICAÇÃO PELO SUPREMO TRIBUNAL FEDERAL SAMYRA HAYDÊE DAL FARRA NASPOLINI VLADMIR OLIVEIRA DA SILVEIRA

inviolabilidade do direito à vida, à liberdade, à igualdade, à segurança e à propriedade, nos termos seguintes:

[...]

LVII - Ninguém será considerado culpado até trânsito em julgado de sentença penal condenatória.

José Afonso da Silva ${ }^{22}$ comenta que se trata de um "enunciado negativo universal", prevalecendo o jus libertatis do indivíduo, em detrimento do jus puniendi do Estado, sendo que a presunção de inocência é algo mais amplo que a de não-culpabilidade.

Outros incisos do artigo 5 vem ao encontro da máxima de proteção da liberdade, tais como LXI que impede a prisão arbitrária, dissociada de uma motivação judicial; o inciso LXII, pela qual os captores estão obrigados a comunicar o Juiz competente sobre a prisão em flagrante do acusado; o inciso LXIII, que obriga a comunicação ao preso de todos os seus direitos constitucionais e legais; o inciso LXIV que dispõem sobre a obrigação de comunicar ao preso a identificação do autor de sua prisão ou de seu interrogatório policial ou judicial.

Também os incisos LXV (relaxamento da prisão ilegal) e LXVI (insubsistência da prisão se houver, para o caso, previsão legal de liberdade provisória, com ou sem fiança), são outros exemplos da mesma regra geral pela liberdade dos indivíduos.

Valério Mazzuoli e Flávio Gomes ${ }^{23}$ arrolam três exigências decorrentes da presunção de inocência adotada pela nossa Constituição:

1. O ônus da prova dos fatos constitutivos da pretensão penal pertence com exclusividade à acusação, sem que se possa exigir a produção por parte da defesa de provas referentes a fatos negativos (provas diabólicas);

2. Necessidade de colheita de provas ou de repetição de provas já obtidas perante o órgão judicial competente, mediante o devido processo legal, contraditório e ampla defesa;

3. Absoluta independência funcional do magistrado na valorização livre das provas.

Os autores também concluem que a imposição de uma condenação somente poderia acontecer após sentença penal condenatória transitado em julgado de um devido processo legal, em que se concederam todas as garantias ao indivíduo para contraditar e convencer o julgador na contrariedade das imputações direcionadas a ele.

Cumprindo a sua função de "guardião da Constituição", em diversas oportunidades, manifestou-se o Supremo Tribunal Federal na defesa da presunção de inocência, o qual se pode

22 GOMES, Flávio; MAZZUOLI, Valério de Oliveira. Comentários à Convenção Americana sobre Direitos Humanos. São Paulo: Ed. Revista dos Tribunais, 2010, p. 158.

${ }^{23}$ GOMES, Flávio; MAZZUOLI, Valério de Oliveira. Comentários à Convenção Americana sobre Direitos Humanos. São Paulo: Ed. Revista dos Tribunais, 2010, p. 217. 
A PRESUNCCÃO DE INOCÊNCIA COMO UM DIREITO HUMANO FUNDAMENTAL NA CONSTITUIÇÃO BRASILEIRA E SUA APLICAÇÃO PELO SUPREMO TRIBUNAL FEDERAL

SAMYRA HAYDÊE DAL FARRA NASPOLINI VLADMIR OLIVEIRA DA SILVEIRA

depreender do paradigmático julgamento do Habeas Corpus $n^{\circ} 84078$ /MG de relatoria no Ministro Eros Grau, de 05 de fevereiro de 2009:

EMENTA: HABEAS CORPUS. INCONSTITUCIONALIDADE DA CHAMADA "EXECUCÃO ANTECIPADA DA PENA". ART. $5^{\circ}$, LVII, DA CONSTITUIÇÃO DO BRASIL. DIGNIDADE DA PESSOA HUMANA. ART. $1^{\circ}$, III, DA CONSTITUIÇÃO DO BRASIL. 1.0 art. 637 do CPP estabelece que "[o] recurso extraordinário não tem efeito suspensivo, e uma vez arrazoados pelo recorrido os autos do traslado, os originais baixarão à primeira instância para a execução da sentença". A Lei de Execução Penal condicionou a execução da pena privativa de liberdade ao trânsito em julgado da sentença condenatória. A Constituição do Brasil de 1988 definiu, em seu art. $5^{\circ}$, inciso LVII, que "ninguém será considerado culpado até o trânsito em julgado de sentença penal condenatória". 2. Daí que os preceitos veiculados pela Lei $n$. 7.210/84, além de adequados à ordem constitucional vigente, sobrepõem-se, temporal e materialmente, ao disposto no art. 637 do CPP. 3. A prisão antes do trânsito em julgado da condenação somente pode ser decretada a título cautelar. 4. A ampla defesa, não se a pode visualizar de modo restrito. Engloba todas as fases processuais, inclusive as recursais de natureza extraordinária. Por isso a execução da sentença após o julgamento do recurso de apelação significa, também, restrição do direito de defesa, caracterizando desequilíbrio entre a pretensão estatal de aplicar a pena e o direito, do acusado, de elidir essa pretensão. 5. Prisão temporária, restrição dos efeitos da interposição de recursos em matéria penal e punição exemplar, sem qualquer contemplação, nos "crimes hediondos" exprimem muito bem o sentimento que EVANDRO LINS sintetizou na seguinte assertiva: "Na realidade, quem está desejando punir demais, no fundo, no fundo, está querendo fazer o mal, se equipara um pouco ao próprio delinqüente". 6. A antecipação da execução penal, ademais de incompatível com o texto da Constituição, apenas poderia ser justificada em nome da conveniência dos magistrados, não do processo penal. A prestigiar-se o princípio constitucional, dizem, os tribunais [leia-se STJ e STF] serão inundados por recursos especiais e extraordinários e subseqüentes agravos e embargos, além do que "ninguém mais será preso". Eis o que poderia ser apontado como incitação à "jurisprudência defensiva", que, no extremo, reduz a amplitude ou mesmo amputa garantias constitucionais. A comodidade, a melhor operacionalidade de funcionamento do STF não pode ser lograda a esse preço. 7. No RE 482.006, relator o Ministro Lewandowski, quando foi debatida a constitucionalidade de preceito de lei estadual mineira que impõe a redução de vencimentos de servidores públicos afastados de suas funções por responderem a processo penal em razão da suposta prática de crime funcional [art. $2^{\circ}$ da Lei n. 2.364/61, que deu nova redação à Lei n. 869/52], o STF afirmou, por unanimidade, que 0 preceito implica flagrante violação do disposto no inciso LVII do art. $5^{\circ}$ da Constituição do Brasil. Isso porque -..- disse o relator ...- "a se admitir a redução da remuneração dos servidores em tais hipóteses, estar-se-ia validando verdadeira antecipação de pena, sem que esta tenha sido precedida do devido processo legal, e antes mesmo de qualquer condenação, nada importando que haja previsão de devolução das diferenças, em caso de absolvição". Daí porque a Corte decidiu, por unanimidade, sonoramente, no sentido do não recebimento do preceito da lei estadual pela Constituição de 1.988, afirmando de modo unânime a impossibilidade de antecipação de qualquer efeito afeto à propriedade anteriormente ao seu trânsito em julgado. A Corte que vigorosamente prestigia o disposto no preceito constitucional em nome da garantia da propriedade não a deve negar quando se trate da garantia da liberdade, mesmo porque a propriedade tem mais a ver com as elites; a ameaça às liberdades alcança de modo efetivo as classes subalternas. 8. Nas democracias mesmo os criminosos são 
A PRESUNÇÃO DE INOCÊNCIA COMO UM DIREITO HUMANO FUNDAMENTAL NÁ CONSTITUIÇÃO BRASILEIRA E SUA APLICAÇÃO PELO SUPREMO TRIBUNAL FEDERAL SAMYRA HAYDÊE DAL FARRA NASPOLINI VLADMIR OLIVEIRA DA SILVEIRA

sujeitos de direitos. Não perdem essa qualidade, para se transformarem em objetos processuais. São pessoas, inseridas entre aquelas beneficiadas pela afirmação constitucional da sua dignidade (art. $1^{\circ}$, III, da Constituição do Brasil). É inadmissível a sua exclusão social, sem que sejam consideradas, em quaisquer circunstâncias, as singularidades de cada infração penal, o que somente se pode apurar plenamente quando transitada em julgado a condenação de cada qual Ordem concedida. (grifos nossos).

De orientação garantista, o Supremo consolidava a impossibilidade da execução provisória de pena, nos termos do art. 637, do Código de Processo Penal, quando da impetração de Recurso Extraordinário, reduzindo a concessão de prisão cautelar aos casos excepcionais, em que estão presentes os requisitos da prisão preventiva.

Porém, passados alguns anos, ao se defrontar com o mesmo tema novamente, o Supremo mudou o seu posicionamento em relação à questão e influenciado por performances midiáticas decidiu no HC 126.292 por maioria de votos que a prisão do acusado antes do trânsito em julgado da sentença condenatória não viola o princípio constitucional da presunção de inocência.

Objeto de muita polêmica, a decisão do Supremo de relatoria do Ministro Teori Zavascki deixou espantados todos aqueles que zelam pelo Estado Democrático de Direito e pelo Processo Penal Constitucional e Democrático:

EMENTA: CONSTITUCIONAL. HABEAS CORPUS. PRINCÍPIO CONSTITUCIONAL DA PRESUNÇÃO DE INOCÊNCIA (CF, ART. 5², LVII). SENTENÇA PENAL CONDENATÓRIA CONFIRMADA POR TRIBUNAL DE SEGUNDO GRAU DE JURISDIÇÃO. EXECUÇÃO PROVISÓRIA. POSSIBILIDADE. 1. A execução provisória de acórdão penal condenatório proferido em grau de apelação, ainda que sujeito a recurso especial ou extraordinário, não compromete o princípio constitucional da presunção de inocência afirmado pelo artigo $5^{\circ}$, inciso LVII da Constituição Federal. 2. Habeas corpus denegado.

Nas declarações de voto dos Ministros encontramos todo tipo de argumento para esta decisão, tais como de que a Constituição não adota a presunção de inocência, e sim o da não culpabilidade, o que é um equívoco, uma vez que a presunção de inocência é uma evolução do princípio da não culpabilidade, conforme estabelece o artigo 8.2 da Convenção Americana de Direitos Humanos, citado acima, o qual o Brasil recepcionou.

Outro argumento encontrado nos votos é sobre a natureza extraordinária dos recursos especial e extraordinário, porém essa condição dos recursos não modifica a situação de ainda não ter transitado em julgado a sentença condenatória, pelo contrário, the atribui essa condição, mesmo porque, como se sabe, muitos casos têm início nos próprios Tribunais, inclusive nos Superiores. 
A PRESUNÇ̃̃O DE INOCÊNCIA COMO UM DIREITO HUMANO FUNDAMENTAL NA CONSTITUIÇÃO BRASILEIRA E SUA APLICAÇÃO PELO SUPREMO TRIBUNAL FEDERAL SAMYRA HAYDÊE DAL FARRA NASPOLINI VLADMIR OLIVEIRA DA SILVEIRA

Mais um argumento falacioso afirma que esses recursos não possuem efeito suspensivo, porém a questão é que se não estiverem presentes os requisitos legais para a prisão cautelar, essa prisão será ilegal, independendo se o recurso possui efeito suspensivo ou não. A sua existência faz com que a sentença condenatória não seja uma sentença transitada em julgado e é isso o que importa.

Do mesmo modo, o suposto "baixo número" desse tipo de recursos também não é razão para excepcionalidades, uma vez que, por ser um ato processual especial, não caberia a todo tipo de situação. Com efeito, e estando presentes os requisitos para sua impetração, o mesmo dá continuidade ao processo, que passa para uma nova etapa, não podendo ser considerado como concluído. Ou seja, trata-se de argumento que não resiste a uma análise isenta e não aprofundada.

Outro argumento recorrente e também bastante utilizado pela mídia e apontado pelos Ministros é o de que o tempo até o trânsito em julgado da sentença é muito grande, o que gera uma sensação de impunidade na população. Ocorre que não se pode corrigir um erro que é da administração da justiça com outro erro que seria violar o estado de inocência somente para fornecer à população uma sensação de justiça efetivada, até mesmo porque poderá ser revertida em caso de futura absolvição.

Portanto, uma pessoa considerada inocente pela Constituição não pode ser usada como um meio para se provar a eficiência de um sistema que é moroso devido a uma série de problemas legais, estruturais, culturais e gerencias típicos das instituições burocráticas brasileiras. No mínimo, seria também uma segunda pena para quem não cometeu novo ilícito.

Por outro lado, a história tem provado a importância da separação entre um juízo técnico e o crivo popular para a proteção dos acusados contra os pré-julgamentos preconceituosos, os linchamentos popular e midiático, feitos a partir da escolha de bodes expiatórios, dos quais as multidões são capazes quando instigadas por falsas verdades persecutórias, principalmente na fase atual das redes sociais.

Nesse contexto, cabe ainda refletirmos e indagarmos a chamada "interpretação conforme a Constituição”. Será que apenas em 2017, após quase trinta anos da atual carta constitucional, o Supremo Tribunal Federal conseguiu decifrar a presunção de inocência? Nesse sentido, nos valemos da literatura para simples reflexão acerca do atual momento reformista do Brasil, em especial, do STF.

Com esse objetivo, melhor autor e conto não há do que "O Reformador do Mundo", de Monteiro Lobato. No mencionado conto, Américo Pisca-Pisca possuía o hábito de colocar defeito 
em tudo. O mundo para ele estava completamente equivocado e a natureza só fazia besteiras. Ocorre que para provar sua tese, Américo resolveu usar o próprio pomar onde estava. Olhando para uma jabuticabeira cheia de pequenas frutas vermelho-escuras e uma enorme abóbora presa ao caule de uma planta rasteira, foi enfático em afirmar que aquilo não fazia sentido. Em outras palavras, não deveria ocorrer justamente o contrário? E na sua precipitada conclusão afirmou com empáfia: "se as coisas tivessem de ser organizadas por mim, eu trocaria as bolas, passando as jabuticabas para a aboboreira e as abóboras para a jabuticabeira". Durante seu cochilo, sonhou com o seu mundo novo que seria construído, até ser interrompido por uma jabuticaba que caiu em seu nariz. Assustado, Américo Pisca-Pisca acorda e percebe o seu equívoco, decidindo abandonar as reformas e deixar tudo como estava.

Pois bem, devemos enquanto juristas e operadores do Direito, ter muito cuidado com os novidadeiros, principalmente em relação às Garantias Fundamentais. Que os novos Pisca-Pisca aprofundem suas reflexões também em relação à crise carcerária, o Pacto Fundamental da nossa sociedade e tudo que foi lenta e solidamente construído pelo próprio Supremo Tribunal Federal.

\section{CONCLUSÃO}

A violação explícita da legalidade, associada à arbitrariedade e violação dos Direitos e Garantias Fundamentais faz com que o exercício de poder punitivo do nosso sistema penal se apresente como um possível genocídio em marcha.

O processo penal não deve ser compreendido pelo operador do Direito como um instrumento de punição por parte do Estado, mas como instrumento de garantia ao processado de que terá um processo no qual poderá defender-se amplamente das acusações que pesam contra si.

Assim, a garantia processual da presunção de inocência, no Estado Moderno Liberal, nasceu devido à busca de um limite ao poder soberano, sendo a razão desse limite os direitos inerentes ao homem, os quais couberam ao Estado preservar, mesmo quando exerce o seu monopólio do direito/dever de punir.

Declarado na Revolução Francesa, e inserido na Constituição daquele país, foi recebido pela Declaração Universal dos Direitos do Humanos, pela Declaração Americana de Direito 

FUNDAMENTAL NA CONSTITUIÇÃO BRASILEIRA E SUA APLICAÇÃO PELO SUPREMO TRIBUNAL FEDERAL SAMYRA HAYDÊE DAL FARRA NASPOLINI VLADMIR OLIVEIRA DA SILVEIRA

Humanos e no Brasil veio também a ser garantido na chamada Constituição Cidadã, a Constituição de 1988.

Diferentemente de autores que tratam a inocência consagrada nas normativas internacionais de proteção aos Direitos Humanos e no artigo $5^{\circ}$ da nossa Constituição Federal como uma "presunção de inocência", ”, entende-se como Eugênio Pacelli de Oliveira, que a denomina "estado ou situação jurídica de inocente".

Assim, o Estado de Inocência como garantia constitucional irá condicionar todo o processo penal determinando que é assim que se deve permanecer o suspeito de um delito, até sentença condenatória irrecorrível.

Portanto, conclui-se que a maioria do Supremo Tribunal Federal decidiu contra a própria Constituição brasileira ao entender que se pode ocorrer a prisão do acusado mesmo antes de sentença penal condenatória.

Por derradeiro, que a exemplo de Américo Pisca-Pisca, o Supremo Tribunal Federal pode reconsiderar suas razões e reestabelecer o estado de inocência no ordenamento jurídico brasileiro.

\section{REFERÊNCIAS}

ANDRADE, Vera Regina Pereira de. A llusão de segurança jurídica. Porto Alegre: Livraria do Advogado, 1995.

BARATTA, Alessandro. Estado del derecho, derechos fundamentales y "derecho judicial". Revista de Ciencia Jurídica, San José da Costa Rica, n. 57, p. 119-134, mayo/ago. 1987.

BARATTA, Alessandro. Direitos Humanos: entre a violência estrutural e a violência penal. Fascículos de Ciências Penais, Porto Alegre, n.2, p. 44-61, abr./jun. 1993.

BOBBIO, Norberto. A era dos direitos. 3 ed. Rio de Janeiro:Elsevier, 2004.

BRASIL. Código de Processo Penal. 19. ed. São Paulo: Saraiva, 2008.

BRASIL. Código Penal. 9. ed. rev. São Paulo: Revista dos Tribunais, 2008.

BRASIL. Constituição (1988). 38. ed. São Paulo: Saraiva, 2008.

CADEMARTORI, Sérgio. Estado de direito e legitimidade: uma abordagem garantista. Porto Alegre: Livraria do Advogado, 1999.

CANÇADO TRINDADE, Antônio Augusto. Tratado de Direito Internacional dos Direitos Humanos. Volume I. Porto Alegre: Editora Sérgio Antônio Fabris, 1997. 
CANOTILHO, José Joaquim Gomes. Direito Constitucional e Teoria da Constituição. 6. ed. Coimbra: Editora Almedina, 1993.

CARVALHO, Salo. Pena e garantias. 2. ed. Rio de Janeiro: Lumen Juris, 2003.

FERNANDES, Antonio Scarance. Processo penal constitucional. 3 ed. São Paulo: Revista dos Tribunais, 2002.

FERRAJOLI, Luigi. Derecho y razón: teoria del garantismo penal. Trad. Perfecto Andrés Ibánez et al. Madri: Trotta, 1995.

FERRAJOLI, Luigi. Direito e Razão: Teoria do Garantismo Penal. São Paulo: Editora Revista do Tribunais, 2006.

GOMES, Flávio; MAZZUOLI, Valério de Oliveira. Comentários à Convenção Americana sobre Direitos Humanos. São Paulo: Ed. Revista dos Tribunais, 2010.

LAFER, Celso. A reconstrução dos direitos humanos: um diálogo com o pensamento de Hannah Arendt. São Paulo: Companhia das letras, 1988.

LOPES, José Reinaldo de Lima. Uma Introdução à História Social e Política do Processo. In: WOLKMER, Antonio Carlos (Org). Fundamentos de história do direito. 2. ed. Belo Horizonte: Del Rey, 2002a.

LOPES, José Reinaldo de Lima. 0 direito na história: lições introdutórias. 2. ed. São Paulo: Max Limonad, 2002b.

LOPES JUNIOR, Aury. Introdução crítica ao processo penal: fundamentos da instrumentalidade garantista. 2. ed. Rio de Janeiro: Lumen Juris, 2005.

LOBATO, Monteiro. O Reformador do Mundo. In: Fábulas de Monteiro Lobato. 1921, p. 3. Disponível em: <

https://mega.nz/\#!nV4G1baC!uQ1G_zV2GjIXw71VXZq05s_ow4QWAQVI034tpBLMXUc > Acesso em: 19 nov. 2018.

MACHADO, Antônio Alberto. Prisão cautelar e liberdades fundamentais. Rio de Janeiro: Lumen Juris, 2005.

NASPOLINI SANCHES, Samyra. H D. F.Direitos humanos e empresa privada no Brasil. IN: COUTO, Mônica Bonetti. (Org); MAILLART, Adriana Silva (Org); MEYER-PFLUG, Samantha Ribeiro (Org); MEZZAROBA, Orides (Coord); NASPOLINI SANCHES, Samyra. H D. F.(Org); SILVEIRA, Vladmir Oliveira da (Coord). Empresa, sustentabilidade e funcionalização do direito. São Paulo: Editora Livraria dos Tribunais, 2011. p 294-307.

OLIVEIRA, Eugênio Pacelli de. Curso de Processo Penal. Belo Horizonte: Del Rey, 2002.

OLIVEIRA, Eugênio Pacelli de. Regimes Constitucionais da Liberdade Provisória. Rio de Janeiro: Lúmen Júris, 2007. 
A PRESUNÇÃO DE INOCÊNCIA COMO UM DIREITO HUMANO FUNDAMENTAL NA CONSTITUIÇÃO BRASILEIRA E SUA APLICAÇÃO PELO SUPREMO TRIBUNAL FEDERAL SAMYRA HAYDÊE DAL FARRA NASPOLINI VLADMIR OLIVEIRA DA SILVEIRA

PIOVESAN, Flávia. Introdução ao Sistema Interamericano de proteção dos direitos humanos: A Convenção Americana dos Direitos Humanos. In. PIOVESAN, Flávia; GOMES, Luiz Flávio (Coord.). O Sistema de Proteção dos Direitos Humanos e o Direito Brasileiro. São Paulo: Ed. Revista dos Tribunais, 2000.

PIOVESAN, Flávia. Direitos Humanos e Justiça Internacional. São Paulo: Ed. Saraiva, 2007.

PRADO, Geraldo. Da Lei de Controle do Crime Organizado: Crítica às Técnicas de Infiltração e Escuta Ambiental. In: WUNDERLICH, Alexandre (Org). Escritos de direito e processo penal em homenagem ao professor Paulo Cláudio Tovo. Rio de Janeiro: Lumen Juris, 2002. p. 125-138.

PRADO, Geraldo.. Sistema acusatório. Rio de Janeiro: Lumen Juris, 2005.

ROCASOLANO, Maria Mendez; SILVEIRA, Vladmir Oliveira. Direitos Humanos: conceitos, significados e funções. São Paulo: Saraiva, 2010.

SILVA, José Afonso da. Curso de Direito Constitucional Positivo. São Paulo: Malheiros, 2008.

VIEIRA, Oscar Vilhena. Direitos humanos: normativa internacional. São Paulo: Max Limonad, 2001.

VIEIRA, Oscar Vilhena. Direitos fundamentais: uma leitura da jurisprudência do STF. São Paulo: Malheiros, 2006.

ZAFFARONI, Eugenio Raúl. Sistemas penales y derechos humanos en América Latina (primer informe). Buenos Aires: Depalma, 1984.

\section{COMO FAZER A REFERÊNCIA DO ARTIGO (ABNT):}

NASPOLINI, Samyra Haydêe Dal Farra; SILVEIRA, Vladmir Oliveira da. A presunção de inocência como um direito humano fundamental na Constituição Brasileira e sua aplicação pelo Supremo Tribunal Federal. Revista Eletrônica do Curso de Direito da UFSM, Santa Maria, RS, v. 13, n. 3, p. 858-875, dez. 2018. ISSN 1981-3694. Disponível em: < https://periodicos.ufsm.br/revistadireito/article/view/33845 >. Acesso em: dia mês. ano. doi: http://dx.doi.org/10.5902/1981369433845. 